\title{
Distant Actors on a Digital C'ampus, or Sharing and Crumbling Pedagogical Responsibility
}

\author{
Hélène Godinet \\ Maître de Conférences par ISPEF (Institut des Sciences et Pratiques d'Education et de \\ Formation), Université Lumière Lyon 2, 16 quai C. Bernard, 69365 LYON 7, France, \\ helene.godinet@univ-lyon2.fr
}

\section{INTRODUCTION}

It is now common to say that the Internet opens up the classroom, that learning has to turn into e-learning with regard to the networked society and the knowledge society. Obviously, learning and teaching tasks are more and more complex. In order to make this complexity explicit, we have observed networkers on a virtual campus.

We focused especially on various competencies that learners and teachers are supposed to have or to acquire when they are collaboratively and interactively networking on a web-based learning platform.

It seems that on a digital campus, the teacher's role is being diluted into various and separated tasks, which require growing expertise. These tasks (for example creating on-line learning materials, defining flexible curricula, on-line tutoring, etc.) are so specialised that one person is not able to do everything. This raises the question: if each task is carried out by an expert or a team of experts, then who is in charge of the learner? Who assumes the pedagogical responsibility?

The original version of this chapter was revised: The copyright line was incorrect. This has been corrected. The Erratum to this chapter is available at DOI: 10.1007/978-0-387-35701-0_35 


\section{BROWSING AN EXAMPLE: FORSE, A DIGITAL CAMPUS FOR EDUCATIONAL SCIENCES}

This Campus, called FORSE (FORmation Ressources en Sciences de l'Education: http://www.sciencedu.org/), is part of the 'campus numérique français' project (http://www.educnet.education.fr/superieur/campus.htm). It was created to respond to specific needs: students who are far from the university because of their personal or professional life; trainers and teachers who decide to complete their knowledge or certify their professional experience. Campus FORSE offers to around 1000 students the opportunity to obtain a diploma (graduate level), by learning at home, over two or four semesters. Students are French speakers, from more than 15 countries. They are certified by European Credits (ECTS).

European teams, experts on each topic, create multimedia resources. Authors are not obliged to be involved in the virtual campus or to network on the learning platform, even if they are teachers in the University. Most of them write their course, sell it to the consortium and do not feel concerned by the way the learning material is used, whether or not it is efficient, whether it makes sense with regard to other modules.

Some teachers and/or researchers agreed to be 'on-line tutors'; they received no specific training. They learn on-line tutoring by doing and sharing with others. They interact with virtual workgroups, using mails, forums and various collaborative tools.

Each level is organized as blended learning: students have to spend some time in the University; at home they receive printed documents and CDROMs; they have to use a learning platform, offering working spaces and on-line resources.

This virtual community involves various actors: learners, teachers, tutors, coordinators, evaluators, administrators, designers and so on.

Reports on this experiment were written by our Master's degree students in educational sciences; they collected various data, that is, questionnaires filled in by students using the platform, interviews with tutors and coordinators, and about 2000 e-mails sent over two years.

\section{RESEARCH RESULTS}

\subsection{Networking competencies}

Firstly, our analysis shows that collaborative networking requires specific competencies. If the technical ability to integrate the web-based training system is easy to acquire (more and more users are computer literate), what 
about the communicative ability? It is not taught at school. Students today still find it difficult to listen to and discuss with teachers and peers. Even if they are encouraged to work in groups, they are learning individually because assessment and diplomas are mostly individual. We are far from the concept of 'collective intelligence.'

Communicating at a distance through ICT is quite new for almost all users. We know how much time it takes to 'speak' using a keyboard, to verbalize feelings and problems by writing sentences instead of interacting face to face; how artificial it is to meet a distant partner on a screen; how frustrating it can be to ask for an explanation by mail and get the answer two or three days later. Do we need to add that communicating within a webbased training system is time consuming? When a tutor interacts with students around the world, what about night and day, working time and holidays?

\subsection{Learning competencies}

Secondly, our analysis shows that being 'interactors' in an ICT learning environment, working within a collaborative learning space cannot simply be ordered. It has to be described in 'meta-capabilities', and not simply by using concepts such as autonomy and motivation. We can list some of them:

- self-studying capability:

$\circ$ information retrieving,

- ability to understand multimedia documents,

o ability to reconstruct information so that it becomes integrated knowledge,

- self management of time

- ability to verbalize (discursive competency):

o to express and share feelings,

o to ask and answer questions,

- to discuss with others, listening, understanding and accepting various points of view

- ability to produce and share documents, as part of collective knowledge:

- self assessment,

- ability to provide a critical feedback,

$\circ$ providing help

In fact, students (even if they are adults, teachers, trainers etc.) are never quite autonomous. They ask for more individual feedback. In answering questionnaires, most of them suggested more time spent at the university as a good way to feel part of a learning community. Only a few of them agreed to 
put their personal work onto the collaborative space. They often sent mails to the tutor, rarely to their peers, and never to the courses' authors.

We know that we are in a period of transition; that these communicative competencies could be developed in our networked society. We know that introducing ICT in learning cannot consist only of 'new packaging for old products'. It also raises questions about the teacher's role.

\subsection{Teaching competencies}

Finally, according to other experiments on networking that we have previously observed, we will try to explain that, in our opinion, the teacher's role is changing, probably because the educational space is changing.

Furthermore, as the 'master-disciple' duo is far away, as the preceptor's status silently disappeared at the beginning of the 20th century, can we imagine that the teacher's status as the responsible guide of an identified learning group might disappear? Can we imagine that he or she would simply join a team of experts, in charge of specific tasks such as the following:

- expert in a domain of knowledge;

- producing and updating on-line resources, including new media (pictures, videos, sound, simulation), cooperating with programmers and designers;

- imagining new teaching methods (not only giving specific content, but also thinking how it could make sense related to other methods or as part of a learning project);

- cooperating with tutors to understand if and how the learning material is useful or not;

- imagining and experimenting with new ways of assessment and certification;

- defining new curricula, knowing that students can learn in different institutes, in a consumer-like way;

- running virtual workshops and newsgroups;

- tutoring;

- managing, marketing, and so on?

This non-exhaustive list shows how complex it is to define the teacher as a professional networker, an expert in specific areas, able to interact and share with various partners, face to face and/or at a distance.

Some of these tasks can be instrumentalized (elaborating curricula, managing the students, managing financial aspects etc.). For example, some ODL prototypes already use virtual tutoring (see for example Exploragraph http://www.esi.umontreal.ca/ dufresne/Publications/HypermediasDufresne.pdf). 
However, we know that it's stupid to imagine that educational robots and agents will replace human guidance. Some questions are so inextricable that only a dialogue with a human tutor can help the student to go further.

Many research reports confirm that human mediation is necessary in the learning process. The concept of school is defined not only by buildings and classrooms; learning and e-learning has something to do with human interaction.

\section{A QUESTION RATHER THAN A CONCLUSION}

It seems important to stress that the growing number of users, scattered across a world-wide, web-based learning space, might dilute pedagogical responsibility.

We are conscious that agreeing to open up the classroom, to integrate networking, offers opportunities to learn without identified teachers. On the other hand we know that the learner needs to meet others, that cognitive conflict is necessary to construct one's understanding and identity. Are we convinced that the teacher is the 'hub' that structures important links, elaborates meaningful tracks and maps between knowledge, the learner and society?

This digital campus can be considered as a case study. We have chosen to observe it as a picture of what the University might be, offering opportunities to learn inside and outside, face-to-face and at a distance, alone or guided. This kind of blended learning might well answer the growing need for life long learning.

\section{REFERENCES}

Castells, M. (2001). The Internet Galaxy. Reflections on the Internet, Business, and Society. Oxford University Press.

Dufresne, A. (2001). Modèles et outils pour définir le soutien dans les environnements hypermédias d'apprentissage. In Hypermedias et Apprentissages. 5ème colloque. INRP.

Godinet, H. \& Klein, A. (2000). The teacher as a mediator in a networked society. In Communications and Networking in Education. Kluwer Academic Publishers.

Godinet, H. (2001). Hypermedias, réseaux, université virtuelle: l'innovation technologique vecteur de l'innovation pédagogique? Conference Proceedings, Lyon. JRES $4^{\text {ème }}$ Journées Réseaux. Retrieved from http://rri.uhp-nancy.fr/documentation/jres2001/

Levy, P. (1994). L'Intelligence Collective. Paris, La Découverte.

OECD (2001). Learning to Change: ICT in Schools. Retrieved from http://www.oecd.org/

Paquette, G., de la Teja, I. \& Dufresne, A. (2000). Explora: An Open Virtual Campus. Montreal: Ed-MEdia'2000. 